\title{
Drenagem urbana do Parque Residencial Beira Rio I no município de Guaratinguetá, SP
}

\author{
Meire Regina de Almeida Siqueira ${ }^{1}$ \\ Marcelo dos Santos Targa ${ }^{2}$ \\ Getulio Teixeira Batista ${ }^{2}$ \\ Nelson Wellausen Dias ${ }^{2}$ \\ ${ }^{1}$ Secretaria da Educação do Estado de São Paulo, Regional de Guaratinguetá, SP. \\ Email: meirereginaa@gmail.com \\ 2 Universidade de Taubaté, Programa de Pós-Graduação em Ciências Ambientais. \\ Email: \{mtarga; nelson.dias\}@unitau.br; gtbatista@gmail.com
}

\begin{abstract}
The objective of this work is to analyze flooding events that frequently affect the residential area called Parque Residencial Beira Rio I in the municipality of Guaratinguetá, State of São Paulo. Data obtained from existing maps and recorded precipitation were used for calculating effective precipitation and surface runoff based on infiltration coefficients derived from the land cover mosaic and related impervious surfaces. Results show that this neighborhood has an area of $330,000 \mathrm{~m}^{2}$, a population of 1,361 inhabitants, a sloping area without vegetation cover facing the residential area, an open drainage system of $0.60 \mathrm{~m}$ diameter tubes, several open pits that capture rain water that descends from the surrounding area allowing a sediment load to enter the tubes. The residential area is located in a low lying plain with cemented curbs, lawn yards, and crossing roads around the lawns that are located in a higher elevation level than the drainage system. Lowering the level of those lawn yards and curbs, as well as recovering the surrounding slopes with forest vegetation should minimize the flooding problems in this neighborhood.
\end{abstract}

Palavras-chave: Sustentabilidade da drenagem urbana, escoamento superficial, low impact development.

\section{INTRODUÇÃO}

Guaratinguetá, município localizado no médio Vale do Paraíba Paulista, desenvolveu-se às margens do Rio Paraíba do Sul, entre as Serras da Mantiqueira e do Quebra-Cangalha. Embora, em 1630, a ocupação urbana tenha ocorrido nas colinas ao redor da Igreja Matriz de Santo Antônio, a maior concentração populacional se encontra nas planícies aluviais do Rio Paraíba do Sul.

Segundo Cardoso Neto (1998), a ocupação urbana se dá após o desmatamento e tem como conseqüências o aumento do escoamento superficial e da erosão do solo, comprometendo os canais e galerias pluviais através de assoreamento. A ocupação das áreas naturais da bacia de inundação do rio Paraíba do Sul e ribeirão Guaratinguetá intensificou a ocorrência de enchentes nessas regiões, aumentando os danos sociais e materiais causados pelas fortes chuvas. Esses locais em geral, são ocupados irregularmente e são as áreas mais prejudicadas por cheias e inundações quando ocorrem chuvas intensas, como a de janeiro de 2000 que ocasionou muitas perdas (PONTES e BERNADES, 2000).

O sistema de drenagem na maioria das cidades brasileiras é conhecido como sistema de microdrenagem e são compostos por conjunto de dutos pluviais ou canais em nível de loteamento ou de rede primária urbana. Este tipo de sistema de drenagem é projetado para atender à drenagem de precipitações com risco moderado. (TUCCI, 2002).

O presente trabalho tem como objetivo determinar a precipitação efetiva e as condições em que ocorre o escoamento superficial na drenagem do Bairro Beira Rio I no município de Guaratinguetá, SP.

\section{METODOLOGIA}

O Bairro Beira Rio em Guaratinguetá, SP (Figura1), à margem esquerda do Rio Paraíba do Sul, foi inaugurado em 1981 com 734 lotes e cuja implantação foi administrada pela Companhia de Desenvolvimento de Guaratinguetá (CODESG). Essa área, no passado, pertencia à fazenda da família Bygton que produziam café junto ao Espigão Guartinguetá-Piaguí. A área destinada ao atual bairro Beira Rio I (Figura 2) era um local com diversas nascentes, lagos, córregos e vegetação diversificada. 
O município de Guaratinguetá apresenta precipitação pluviométrica média anual de aproximadamente $1.398 \mathrm{~mm}$ (SILVA, 2000). O embasamento é formado por depósitos aluviais recentes do tipo argilo-siltoso e sílitico-arenoso, com solos rasos, com nível freático que varia de 0,60m a 1,30m, em média (COLTRINARI, 1975). A área da bacia do Beira Rio está inserida na Província Geomorfológica do Planalto Atlântico, pertencente ao relevo do Médio Paraíba, (SOARES, 2005).

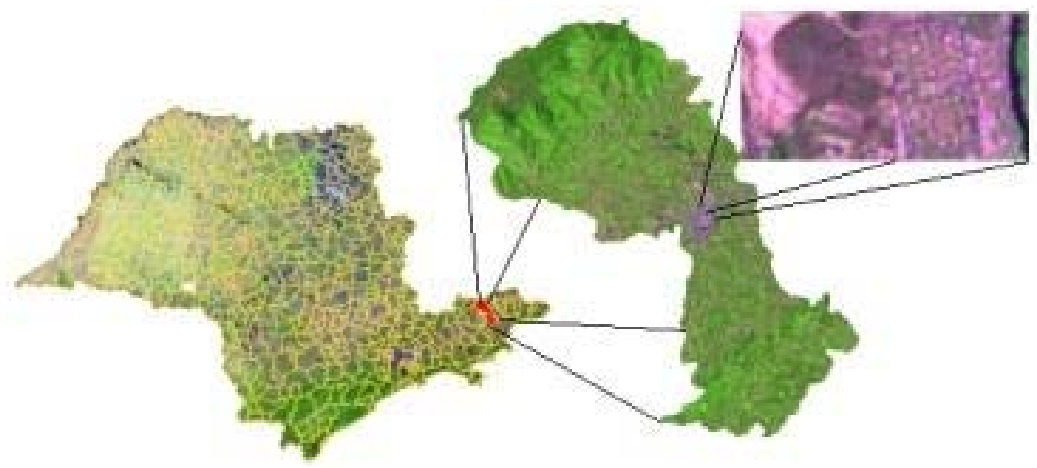

Figura 1: Localização do bairro Beira Rio I em Guaratinguetá, SP.

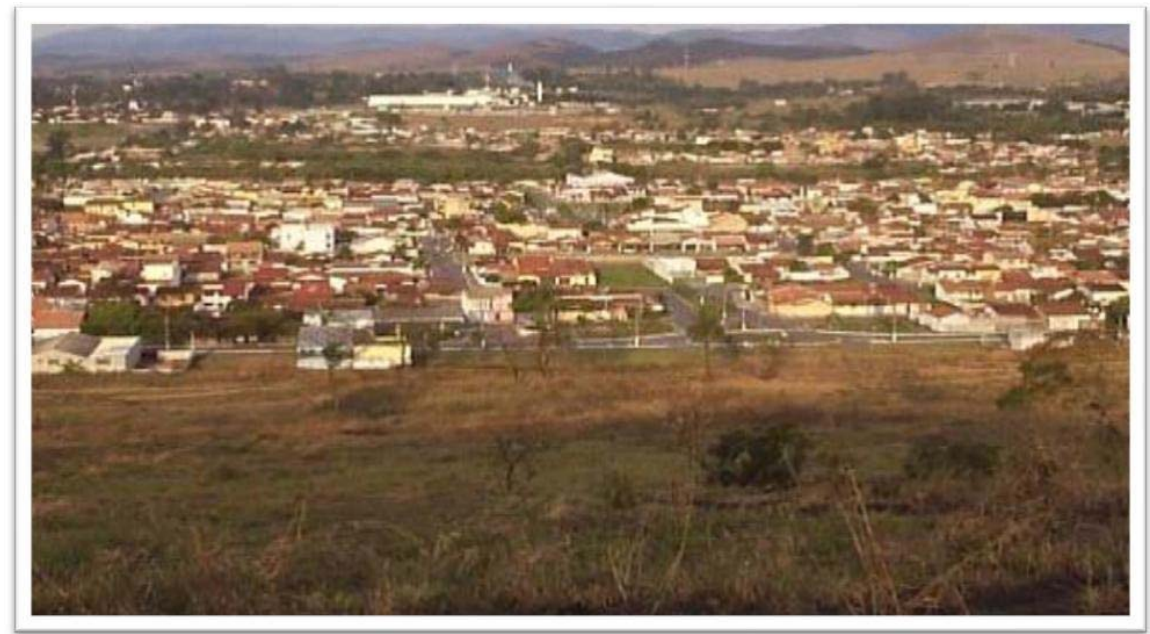

Figura 2. Vista Panorâmica do Bairro Parque Residencial Beira Rio I.

A quantificação do escoamento superficial foi feita por meio do Método NRCS (1997) desenvolvido pelo Soil Conservation Service - USDA, levando em consideração três situações: a) situação atual de uso e cobertura do solo do Bairro Beira Rio I; b) situação de urbanização total do espigão Guaratinguetá - Piaguí; c) situação de reposição florestal do espigão Guaratinguetá - Piaguí.

O procedimento de determinação do escoamento superficial tem por base a definição do parâmetro CN (Curva Número), o qual depende de fatores como tipo de solo, condições de uso e ocupação do solo e umidade antecedente do solo e nesse trabalho segui as recomendações da PMSP (1999) e do Haested Metods (2004). O cálculo do Escoamento Superficial Direto em mm foi determinado por meio das Equações [1] e : [2]

$$
P_{e}=\frac{(P-0,2 * S)^{2}}{(P+0,8 * S)}
$$

$S=\frac{25400}{C N}-254$

Onde: 
$\mathrm{P}_{\mathrm{e}}=$ Precipitação efetiva que potencialmente gera o escoamento superficial em mm;

$\mathrm{P}=$ Precipitação máximaem mm;

$\mathrm{S}$ = Infiltração potencial máxima em mm

CN = Número da Curva, admensional

A bacia apresenta área de $1,3 \mathrm{~km}^{2}$, utilizou-se os valores das precipitações máximas com duração de 30 minutos (Tempo de Concentração - Kirpich) com tempo de retorno variando de 2, 5, 10, 15, 20, 25, 50 e 100 anos, do Posto Meteorológico de Guaratinguetá, SP, Prefixo: 02-077 Fazenda Monte Verde com LAT: 22G43M, LONG: 45G21M e ALT: 900 metros do estudo de Intensidade-duração-frequência ( MARTINEZ JUNIOR e MAGNI 1999).

Em termos de escoamento superficial a composição do Curva Número (NRCS, 2004) foram considerados para a condição atual, as classes de uso e cobertura do tipo asfalto, terreno baldio em boas condições, espaços abertos relvados, lotes 65\% impermeáveis, zonas florestais em condição ruim, todos em tipo de solo $\mathrm{D}$ e pastagem em má condição em solo tipo B. Para a condição de reflorestamento com espécies nativas da área do Espigão Piagui, substituiu-se a classe pastagem por zonas florestais em boa condição.

\section{RESULTADOS E DISCUSSÃO}

Na Figura 3 é demonstrado o crescimento urbana de Guaratinguetá, SP e APP em área urbana obtida por meio de técnicas de geoprocesamento no software SPRING (CÂMARA, 2003) a partir da Carta do IBGE(1974) na escala de 1:50.000 e por meio de imagem ASTER de 2006. A análise das imagens e cartas georreferenciadas permitiu observar que a área urbana de Guaratinguetá nas últimas quatro décadas praticamente dobrou (Figura 3). Houve uma maior concentração urbana junto às áreas de planícies inundáveis da margem esquerda, que cresceu de forma irregular, sem nenhuma preocupação com as áreas de preservação permanentes (APPs) do Rio Paraíba do Sul.

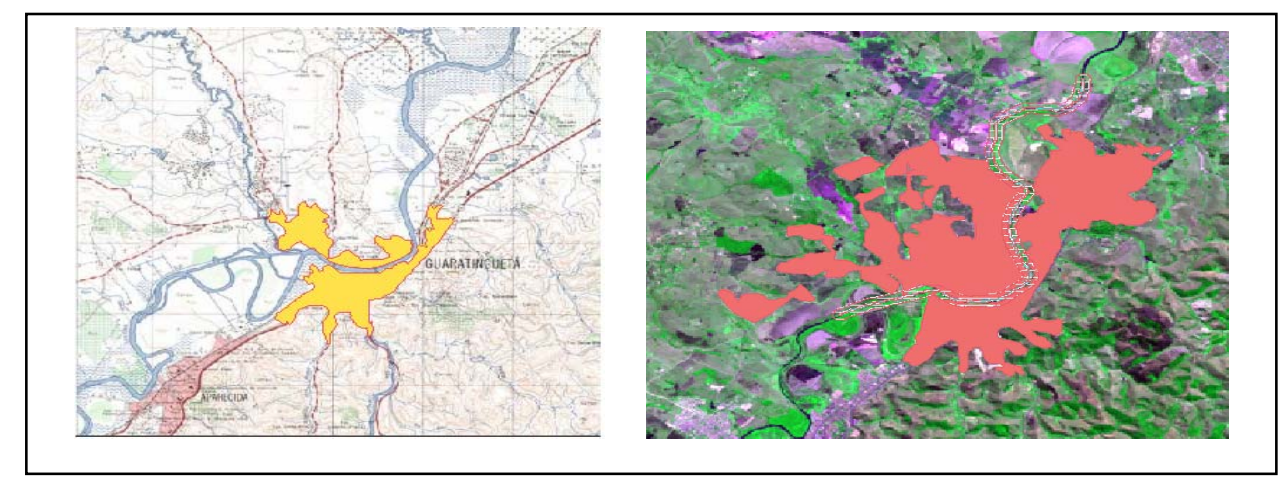

Figura 3. Crescimento da área urbana de Guaratinguetá, SP o período de 1974 a 2006.

No início, quando os lotes foram marcados e liberados para construção, o bairro Beira Rio I não possuía pavimentação, sistema de drenagem e iluminação publica e dessa forma, durante as chuvas torrenciais as ruas tornavam-se verdadeiros rios com a água correndo, devido a topografia, pela região central do bairro em direção à Avenida Contorno Leste, onde havia um único canal de drenagem até o Rio Paraíba do Sul.

As obras de pavimentação e drenagem aconteceram em 1996, quando boa parte das casas já haviam sido construídas. Devido a baixa declividade da porção central do bairro, fez-se necessária a elevação do nível das ruas por aterramento, deixando muitas casas abaixo do nível de drenagem superficial e conseqüentemente vulneráveis às inundações. O bairro possui $330.000 \mathrm{~m}^{2}$ e aproximadamente 554 residências construídas que ocupam mais de $80 \%$ do bairro. Tem uma população de 1361 habitantes cujo rendimento familiar mensal, em sua grande maioria, está entre 5 e 10 salários mínimos e, portanto, pode ser considerado um bairro de classe média (IBGE, 2000). 
As visitas em loco evidenciaram no Bairro Beira Rio I os seguintes elementos de microdrenagem (SILVEIRA 2002 e TUCCI 2002),: Galeria, Bocas-de-lobo, Tubos de ligações, Sarjetas, Poços de Visita. O bairro conta com três sistemas de galerias feitas em concreto e com diâmetro de 1,5 metros, as quais são cobertas por canteiros gramados e são responsáveis por escoar a água da chuva transmitida por meio de tubos de ligações.

A Galeria 1, localizada no contorno sul do bairro (Figura 3), capta o escoamento superficial da ala sul e também dos bairros vizinhos (Portal das colinas e Parque das Alamedas).

O Bairro Beira Rio I tem como contorno a oeste o Espigão Guaratinguetá - Piaguí que é um divisor das bacias dos ribeirões Guaratinguetá e Piaguí o qual apresenta altitude média de $575 \mathrm{~m}$, com topos amplos e arredondados, declividade entre 20 e 30\% e vertentes ravinadas com perfis convexos retilíneos, possuindo drenagem de média e baixa densidade (COLTRINARI, 1975).

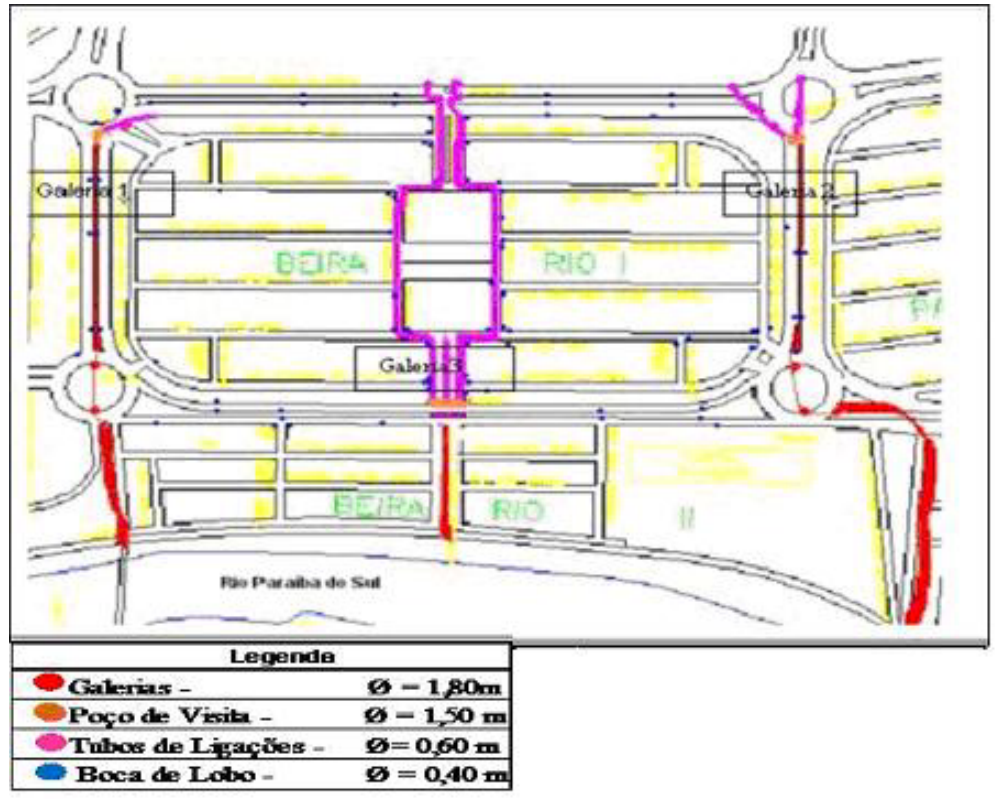

Figura 4 Mapa dos elementos do sistema de drenagem do Bairro Beira Rio I.

Fonte: adaptado da Carta Municipal 1:10.000 (PMG)

Da Figura 4 percebe-se que a Galeria 1,localiza-se no contorno sul do bairro e capta o escoamento superficial da ala sul. AGaleria 2 passa na Avenida Francisco Lopes Netto, limítrofe com Bairro Parque do Sol, capta o escoamento superficial do Bairro Beira Rio I e Parque do Sol, bem como o escoamento que desce do Espigão Piaguí com grande carga de sedimentos. A Galeria 2 também é coberta por canteiro até atingir um poço de visita no Bairro Jardim Esperança, após o que segue em canal até o Rio Paraíba. A Galeria 3 encontra-se no limite entre o Bairro Beira Rio I e o Bairro Beira Rio II e recebe água dos tubos de ligação de diâmetro de 0,60m, os quais ligam as bocas-de-lobo e a Galeria 3. Os tubos de ligação percorrem a região central do Bairro Beira Rio I, em três redes diferenciadas e lançam o escoamento superficial em 2 poços de visita.

O primeiro poço de visita de profundidade de aproximada 1,50m encontra-se no canteiro central da Avenida Professor João Francisco Rodrigues Alckmin, é o ponto de convergência, também da rede de boca-de-lobo do canteiro central desta mesma avenida. O segundo com aproximadamente 1,80m está localizado no Bairro Beira Rio II, e se constitui no início da Galeria 3. Em geral, foi observado o mau estado de conservação dos poços de visitas e das bocas-de-lobo, os quais na maioria das vezes encontram-se cheios de resíduos sólidos, de toda a sorte, cobertos com vegetação e com as entradas desprovidas de grades e parcialmente impedidas por resíduos sólidos.

O espigão a montante do Bairro é desprovido de cobertura vegetal do tipo floresta, mas conta com cobertura de pastagem rala e degradada que gera, durante chuvas torrenciais de verão, grandes escoamentos e alagamento nos bairros Beira Rio e demais bairros subjacentes, os quais têm suas ruas invadidas por água e sedimentos. Como forma de diminuir a força motriz das águas descem pelo Espigão Piagui, a Prefeitura Municipal construiu uma série de curvas de nível e diques de contenção (Figura 5) que realmente auxiliam na redução do escoamento superficial e promovem 
a infiltração de água no solo, conforme (BERTONI e LOMBARDI NETO, 1998). Por outro lado construiu também valetas (Figura 6) que direcionam o fluxo para as bocas -de-lobo, as quais recebem a água com elevada concentração de sedimentos e os lançam diretamente na rede de drenagem.

Outro aspecto que interfere diretamente na forma como ocorre o escoamento é que no Espigão ainda existem nascentes, mas seus córregos que tinham os exutórios naturais no Rio Paraíba, foram para a construção do Bairro, canalizados e/ou desviados.

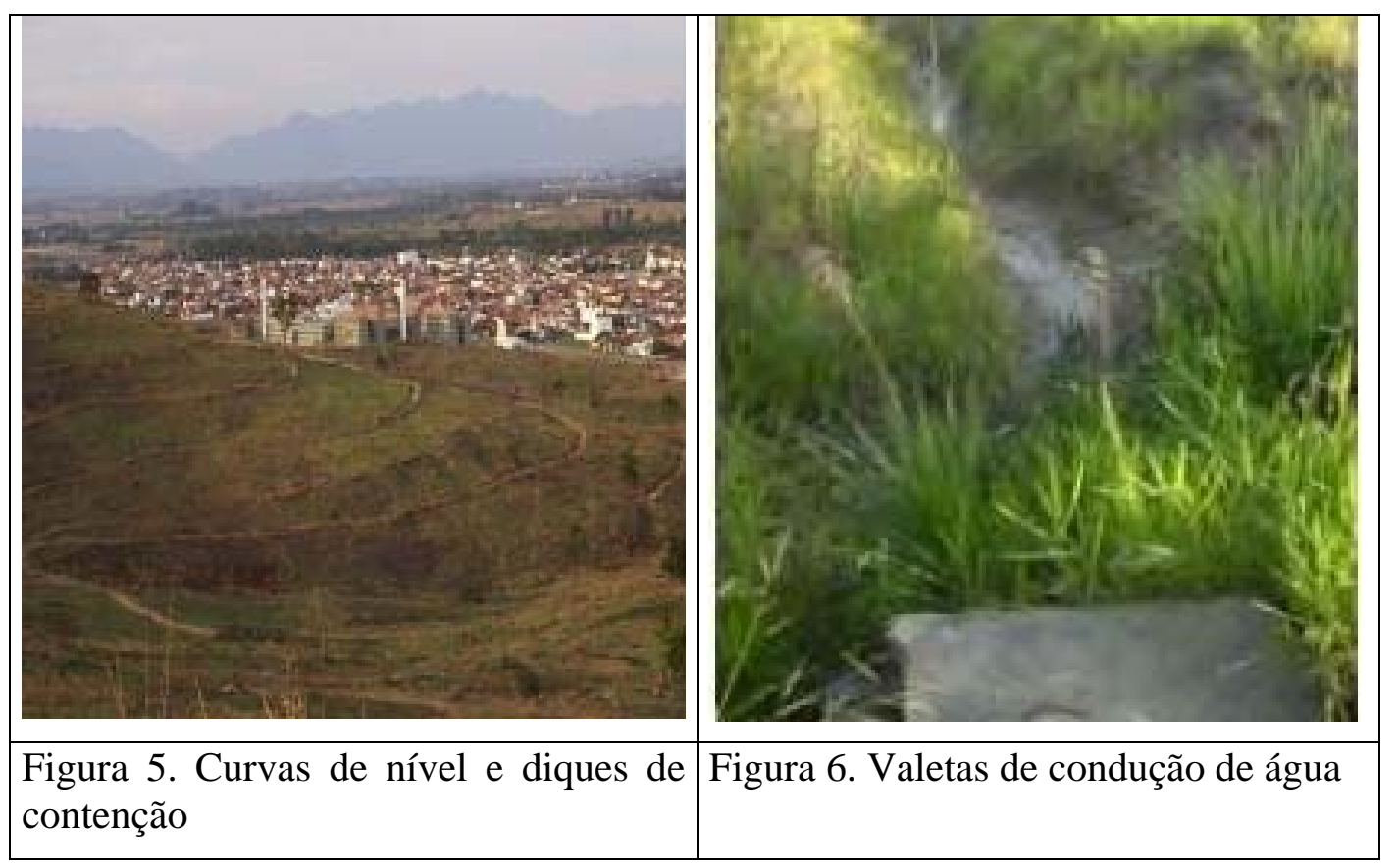

As Bocas-de-lobo com diâmetro de 0,40 m concentram-se na porção central do bairro, onde há maior declividade, são comuns, também, nas proximidades dos canteiros que contornam o bairro e são as menos conservadas de todos os elementos de drenagem.

Os padrões de tipo de solo, classe de uso e cobertura do solo, área de cada classe e Curva Número selecionado, encontra-se na Tabela 2.

Tabela 2. Tipos de solo, classes de uso e cobertura, áreas de cada classe e Curva Número definidos como padrão.

\begin{tabular}{|c|l|c|r|r|}
\hline \multirow{2}{*}{ Tipo Solo } & \multicolumn{1}{|c|}{ Classes de Uso e Cobertura } & Área (ha) & \multicolumn{1}{c|}{$\%$} & CN \\
\hline D & Asfalto & 7,71 & 9,73 & 98 \\
\hline D & Terreno Baldio (boas condições) & 4,42 & 5,58 & 80 \\
\hline D & Espaços abertos relvados & 3,40 & 4,29 & 80 \\
\hline D & Lotes (65\% impermeável) & 22,11 & 27,89 & 92 \\
\hline D & Zonas florestais (cobertura ruim) & 0,47 & 0,59 & 83 \\
\hline B & Pastagem (má condição) & 41,16 & 51,92 & 67 \\
\hline B & Zonas florestais (cobertura boa) & 41,16 & 51,92 & 55 \\
\hline B & Lotes (65\% impermeável) & 41,16 & 51,92 & 85 \\
\hline
\end{tabular}

Os resultados de ponderação da Curva Número, Infiltração Potencial para cada situação de uso e cobertura calculados pela [Eq. 2] encontra-se na Tabela 3. 
Tabela 3. Curva Número ponderado (CNpond) e Infiltração potencial (S - mm) para cada tipo de tratamento a ser aplicado no Espigão Piaguí.

\begin{tabular}{|l|c|c|}
\hline Tipos de Uso e Cobertura & CN pond & Infiltração Potencial`(S mm) \\
\hline Atual & 84,60 & 46,23 \\
\hline Impermeabilização (65\%) do Espigão & 87,71 & 35,59 \\
\hline Reflorestamento do Espigão & 72,13 & 98,14 \\
\hline
\end{tabular}

Os resultados de Precipitação efetiva em função das precipitações máximas com duração de 45 minutos e tempo de retorno variando de 2, 5, 10, 15, 20, 25, 50 e 100 anos, em função dos valores de CNpond e Infiltração potencial (S) para cada tratamento, encontram-se na Figura 7.

Os resultados de Precipitação efetiva para os tempos de retorno variando de 2, 5, 10, 15, 20, 25, 50 e 100 anos para cada tratamento dado ao Espigão Piagui, encontram-se na Figura 8.

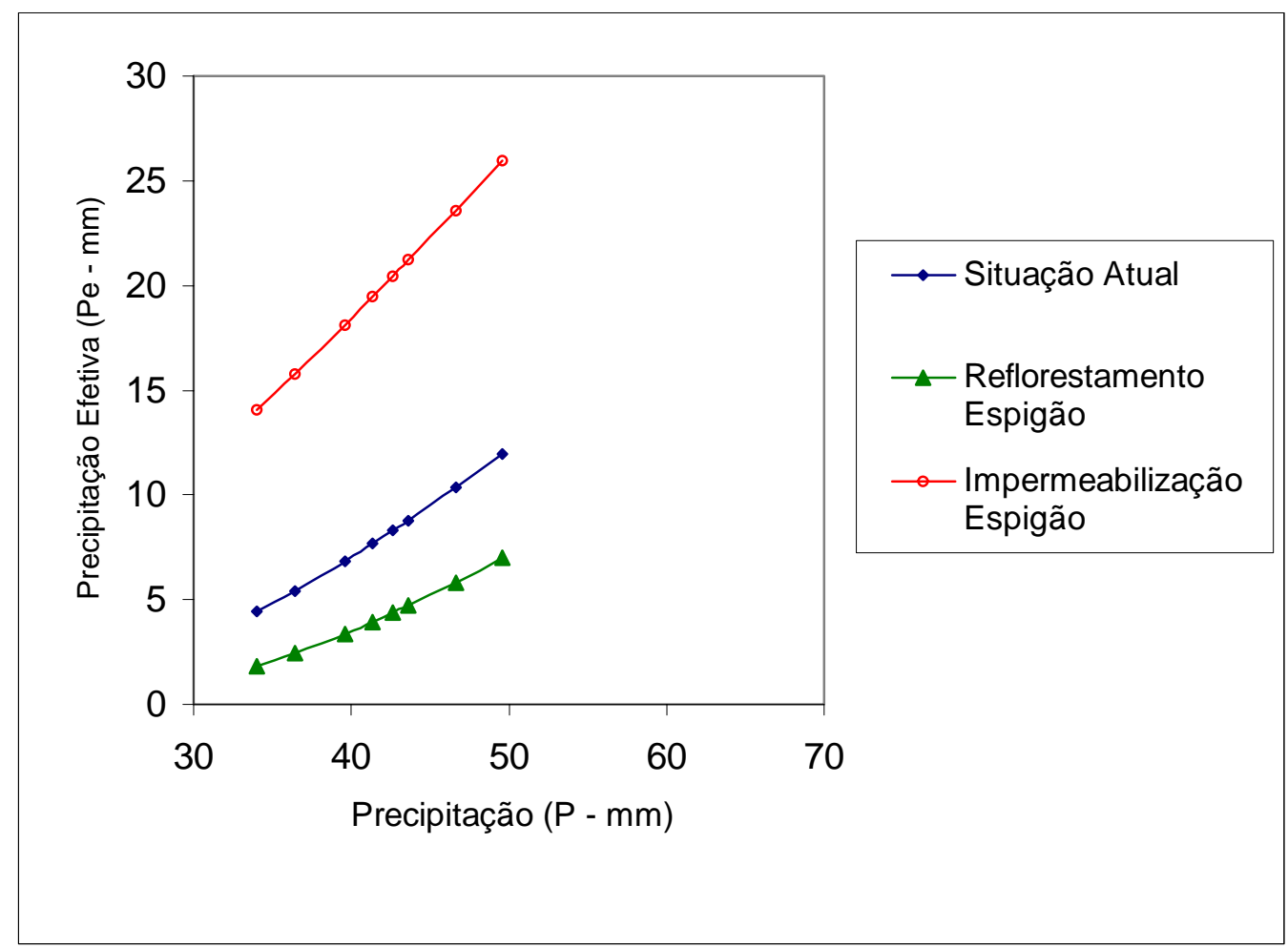

Figura 7. Precipitação Efetiva ( Pe-mm) para as Precipitações Máximas (P - mm) em função dos tratamentos dados ao Espigão Piagui.

Os resultados da análise do escoamento superficial demonstram que se a PMG promover o repovoamento florestal com essências nativas no Espigão Piagui a montante do bairro Beira Rio I, ocorrerá uma significativa redução no escoamento superficial pela metade a Precipitação efetiva, ao passo que a impermeabilização do Espigão mesmo na base de $65 \%$ da área, o escoamento superficial triplicará agravando ainda mais o problema das inundações freqüentes no bairro.

Apesar da existência de todos os elementos de drenagem sugeridos por Tucci (2002), eles se mostram ineficientes frente as chuvas torrenciais de verão, provocando alagamentos na região central do bairro, rotatórias, e suas laterais, principalmente, após a criação de novas vias de acesso ao bairro que facilitaram a entrada do escoamento superficial dos bairros vizinhos e sedimentos do Espigão Piaguí.

Além de uma constante manutenção, o sistema de drenagem urbana do Bairro Beira Rio I poderia ser adaptado para o emprego do modelo LID ("Low Impact Development ") Desenvolvimento Urbano de Baixo Impacto que foi desenvolvido por agências do Departamento de Defesa Americano (USDD, 2004) e consiste em uma estratégia de gerenciamento da água chuva com a finalidade de manter ou restaurar o ciclo hidrológico natural. Esse sistema sugere que haja 
um planejamento urbano que considere o ambiente natural, evitando ao máximo a movimentação de terras e respeite as condições das calhas de drenagem natural, de modo a integrar a ocupação urbana ao meio natural (SOUZA et al., 2005).

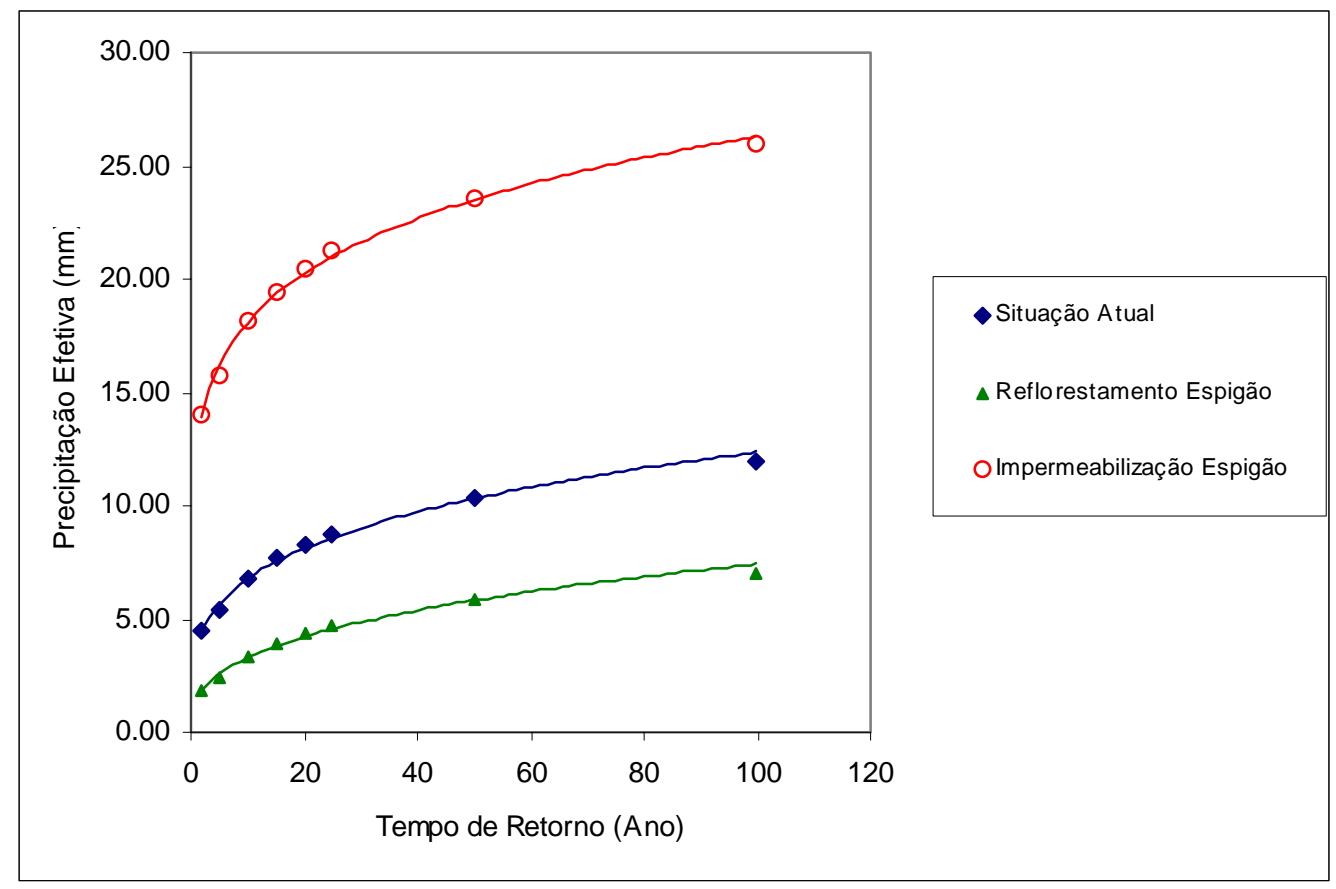

Figura 8. Precipitação Efetiva em função dos Tempos de retorno da chuva máxima em função dos diferentes tratamentos dados ao Espigão Piagui.

Algumas dessas técnicas poderiam facilmente ser aplicadas ao Parque Residencial Beira Rio I, promovendo melhoramento na qualidade do escoamento superficial local e diminuindo os impactos por ele causados como, por exemplo: 1. Repovoamento florestal na área de encosta conforme determina a Lei 4771/65 para APPs (BRASIL, 1965) e vedação dos tubos ao lado da encosta; 2. Direcionamento de fluxos de áreas pavimentadas para áreas vegetadas estabilizadas e de baixo potencial erosivo; 3. Estímulo ao escoamento raso em áreas vegetadas; 4 . Maximizar o uso de sistemas de canais abertos; 5. Aumentar e melhorar a vegetação do local e dos lotes; 6. Criação de jardins de bio-detenção

\section{CONCLUSÕES}

Pela análise do escoamento superfical em nehuma hipótese deve-se urbanizar a área do Espigão Piagui, sob o risco de triplicar o escoamento superficial. Ações como o repovoamento florestal da encosta a montante do bairro (espigão) e a construção de reservatórios de água de chuva adaptados a obras paisagísticas podem reduzir o escoamento superficial pela metade e colaborar para melhoria da qualidade do escoamento superficial e adjacências promovendo um maior equilíbrio do ciclo hidrológico local e melhoria na qualidade de vida de seus habitantes.

\section{REFERÊNCIAS BIBLIOGRÁFICAS}

BERTONI, J.; LOMBARDI NETO. F. Conservação do solo. 1. ed. Piracicaba: Livroceres, 1985, 392p.

BRASIL. Lei Federal No 4.771, de 15 de setembro de 1965 (Institui o Novo Código Florestal Brasileiro), 1965.

CARDOSO NETO, A. Sistemas urbanos de drenagem. Florianópolis, Laboratório de Drenagem do Departamento de Engenharia Sanitária da Universidade Federal de Santa Catarina, 1998. 19 p. Documento interno. 
COLTRINARI, L.Z. Contribuição à Geomorfologia da Região de Guaratinguetá - Aparecida. Tese de doutorado da USP, 1975.

IBGE. Estatcart 2000: Dados Censitários do Município de Guaratinguetá, 2000.CD-ROM.

MARTINEZ JÚNIOR, F.; MAGNI, N. L. G. Equações de chuvas intensas do Estado de São Paulo. Convênio Departamento de Águas e Energia Elétrica (DAEE) e Escola Politécnica da Universidade de São Paulo. São Paulo, 1999.

NRCS. Estimation of Direct Runoff from Storm Raifall. In: Hydrology. National Engineering Handbooks. National Resources Conservation Service . USDA, Washington, USA, 1997.Part 630. Cap. 10 79p. disponível em www.ftw.nrcs.usda.gov e consultado em abril de 2006.

PMG. Carta Municipal 1:10.000. Prefeitura Municipal De Guaratinguetá; Secretaria de Planejamento, Guaratinguetá-SP. 2006.

PMSP. Diretrizes Básicas para Projetos de Drenagem no Município de São Paulo. Prefeitura Municipal de São Paulo. Fundação Centro Tecnológico de Hidráulica. 1999. 289p.

PONTE, C. P.; BERNARDES, G. P.. Análise e soluções mitigadoras das regiões afetadas pela inundação de janeiro de 2002, Município de Guaratinguetá. In: I Seminário Nacional de Impactos Ambientais Urbanos, 2002, Curitiba. SENISA-URB, 2002.

SIQUEIRA, M. R. A.; BATISTA, G.T.; TARGA, M.T.; CATELANI, C.S. Mapeamento das áreas de inundações das planícies aluviais de Guaratinguetá através de técnicas de Geoprocessamento. In: Primeiro Seminário de Sensoriamento Remoto e Geoprocessamento para Estudos Ambientais no Vale do Paraíba, 2006, Taubaté. Anais GEOVAP 2006: Primeiro Seminário de Geoprocessamento do Vale do Paraíba, Taubaté, Brasil, 7, 2006. V. 01. P. 54-64.

SILVA, J. U. L. Balanço hídrico na região de Guaratinguetá-SP-Brasil. In: Congresso de Engenharia Sanitária, 2000. Balanço hídrico.

SOARES, P. V. As Interrelações de elementos do meio físico natural e modificado na definição de áreas potenciais de infiltração na porção paulista da Bacia do Rio Paraíba do Sul. Tese Doutorado. Universidade Estadual de Campinas, UNICAMP, Campinas, 2006.

SOUZA, C. F.; TUCCI, C. E. M. . Desenvolvimento urbano de baixo impacto. In: Simpósio de Recursos Hídricos do Sul RS-SC-PR, 2005, Santa Maria. Simpósio de Recursos Hídricos do Sul RS-SC-PR. Santa Maria: ABRH, 2005. v. 1. p. 1-19.

TUCCI, C. E. M. Impactos da variabilidade climática e o Uso do solo sobre os recursos hídricos. In: Fórum Brasileiro de Mudanças Climáticas - Câmara Temática de Recursos Hídricos, Brasília, 2002, maio.

USDD. Unified facilitieis Criteria (UFC). Designing: low impact development manual. UNITED STATES. Department of Defense - USA. 2004. disponível em http://www.ccb.org. <Acesso: 10 de Julho de 2007>. 